\title{
Endoscopic necrosectomy through the major duodenal papilla under fluoroscopy imaging
}

Marian Smoczyński, Mateusz Jagielski, Magdalena Siepsiak, Krystian Adrych

Department of Gastroenterology and Hepatology, Medical University of Gdansk, Gdansk, Poland

Submitted: 18 June 2015

Accepted: 25 September 2015

Arch Med Sci 2018; 14, 2: 470-474

DOI: 10.5114/aoms.2016.61903

Copyright $\odot 2016$ Termedia \& Banach

In the last twenty years we have observed development of minimally invasive techniques of treatment of pancreatic necrosis [1, 2]. Those methods include procedures handled with the use of an endoscope, laparoscope or nephroscope, enabling a transperitoneal, retroperitoneal, transmural or transpapillary approach to necrotic collection [1, 2]. The choice of access to the necrosis depends on its location and spread.

A meta-analysis of 8 studies revealed that in 286 patients with infected pancreatic necrosis, percutaneous drainage, being the only way of access to the necrosis, was efficient in $44 \%$ of patients [3]. The average rates of complications and mortality related to treatment were respectively $28 \%$ and $20 \%$ [3]. The next meta-analysis of 11 studies involving 384 patients revealed that in over half of them percutaneous drainage was an efficient method of treatment [4].

In minimally invasive techniques of treatment of walled-off pancreatic necrosis (WOPN) by a retroperitoneal approach, an inflexible nephroscope or flexible endoscope is inserted into the cavity of the necrosis, and then necrotic tissues can be removed by different endoscopic instruments [5, 6]. The desired effect of treatment by a minimally invasive retroperitoneal approach was achieved in $75-93 \%$ of patients [5-11]. Complication were reported in $24-88 \%$ of patients and mortality in $0-25 \%$ of them [ $5-11]$.

Transmural endoscopic drainage of pancreatic necrosis is based on the removal of necrotic content through a stoma formed between the lumen of the gastrointestinal tract and the cavity of the necrotic collection [12]. It is possible to take advantage of transpapillary drainage in treatment of pancreatic necrosis when the main pancreatic duct is damaged [13]. Patients without clinical improvement despite applied endoscopic drainage require necrosectomy. Endoscopic treatment of WOPN is efficient in $81-91 \%$ of patients. Complications were observed in $14-26 \%$ of patients [14-17].

Laparoscopy is found to be the next technique of pancreatic necrosis treatment consisting in access to the necrosis by a transperitoneal approach. It is said to be the least commonly applied method of minimally invasive WOPN treatment and also the least described in the literature. Successful treatment of pancreatic necrosis by laparoscopic techniques was reported in $74-90 \%$ of patients with a complication rate of $13-48 \%$ and mortality of $0-11 \%$ [18-21].

Direct comparison of above-mentioned results is hard not only due to the different size and variety of patient groups, but particularly due to differences between techniques of treatment and aggressiveness of used therapy. The period of observation also differs.

\author{
Corresponding author: \\ Mateusz Jagielski MD \\ Department of \\ Gastroenterology \\ and Hepatology \\ Medical University of Gdansk \\ 17 Smoluchowskiego St \\ 80-214 Gdansk, Poland \\ Phone: +48583493640 \\ Fax: +48583493650 \\ E-mail: jagiel@gumed.edu.pl
}


The choice of WOPN treatment method should depend on the experience of the medical center.

In infected walled-off pancreatic necrosis a stepup approach should be the first type of therapeutic procedure. This strategy can be applied with different ways of access to the cavity of the necrosis. Expansion of the access to the necrosis creates better drainage conditions.

Herein, we introduce a description of successful treatment of a patient with WOPN using minimally invasive techniques. In the applied treatment two ways of access to the cavity of the necrosis were used. First the endoscopic transmural drainage was made, since the distance between the lumen of the gastrointestinal tract and the cavity of the necrosis did not exceed $1 \mathrm{~cm}$ on endoscopic ultrasonography. Thereafter endoscopic transpapillary drainage was performed, because necrotic collection had communicated with the main pancreatic duct.

According to the first published scientific reports concerning endoscopic drainage of walledoff pancreatic necrosis, a small fistula (10-12 mm) between the lumen of the gastrointestinal tract and a cavity of the necrosis used to be made [16, 22]. With the spread of this method the diameter of the fistula was widened to $2 \mathrm{~cm}[23,24]$. Dilation of the cystostomy up to $20 \mathrm{~mm}$ enabled fiberoscope entrance to the cavity of the necrosis and performance of endoscopic necrosectomy $[23,24]$. In the described case the endoscopic necrosectomy was performed without the necessity of insertion of the fiberoscope into the cavity of the necrosis. In our study necrotic tissues were re- moved through the major duodenal papilla using a Dormia basket and under fluoroscopy imaging, which gave beneficial clinical effects.

A 65-year-old woman after acute necrotizing gallstone-induced pancreatitis was admitted to our department in order to begin endoscopic treatment of infected WOPN in May 2013. At admission the patient suffered from abdominal pain, fever and shivers lasting for 2 weeks. Laboratory blood tests indicated elevated levels of amylase, lipase and markers of inflammation. Contrast-enhanced computed tomography (CECT) of the abdomen showed walled-off collection $(202 \times 130 \times$ $240 \mathrm{~mm}$ ) with tissue fragments, extending down the abdomen and drawing aside surrounding organs (Figure 1). After being explained the possible treatment complications and forecasted time of hospitalization, the patient expressed consciously her acceptance of endoscopic treatment of the WOPN. During hospitalization the fistula between the posterior wall of the stomach and the collection of the necrosis was made under endoscopic ultrasonography, resulting in an outflow of necrotic content. Using a high-pressure balloon the fistula was widened to a diameter of $20 \mathrm{~mm}$. Afterwards through the stoma a double pigtail 8.5-Fr stent and a 8-Fr nasocystic drain were inserted (Figure 2) in order to irrigate the collection $(200 \mathrm{ml}$ saline solution every $4 \mathrm{~h}$ ). Based on the results of a culture of the necrotic content the patient received antibiotic therapy - piperacillin with tazobactam $(4 \mathrm{~g}+0.5 \mathrm{~g})$ intravenously every $8 \mathrm{~h}$ for 32 days. After the first 12 days of active transmural drainage, endoscopic retrograde pancreatography was

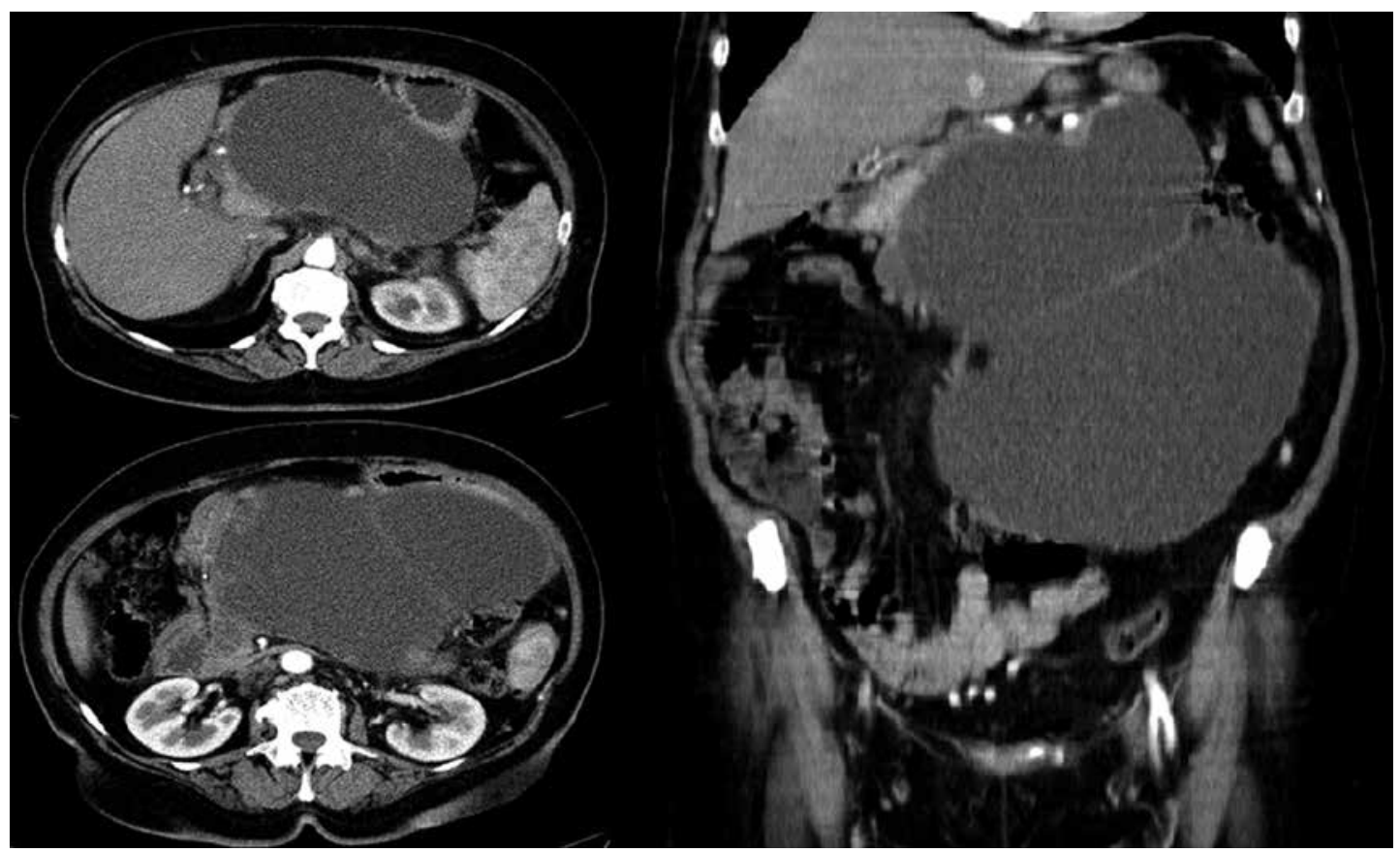

Figure 1. Contrast-enhanced computed tomography of the abdomen performed before the treatment 


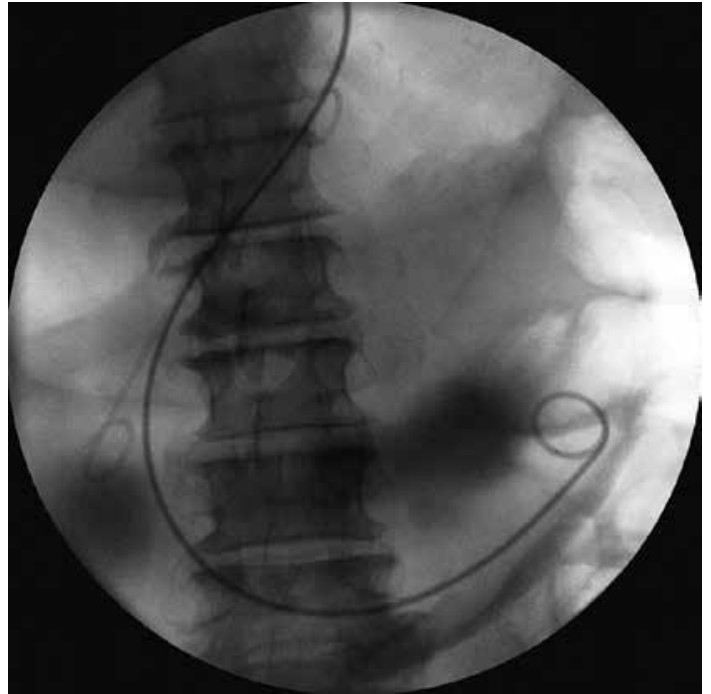

Figure 2. Transmural drainage of the WOPN

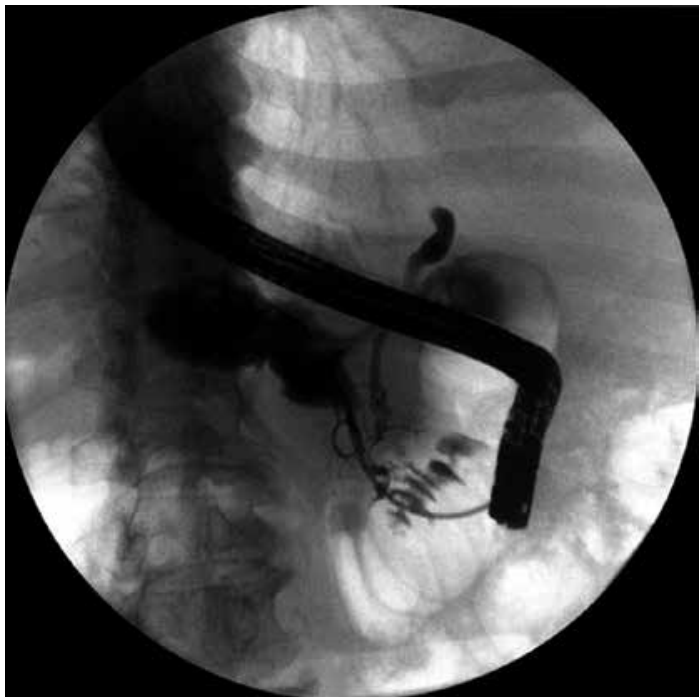

Figure 3. Complete disruption of the main pancreatic duct

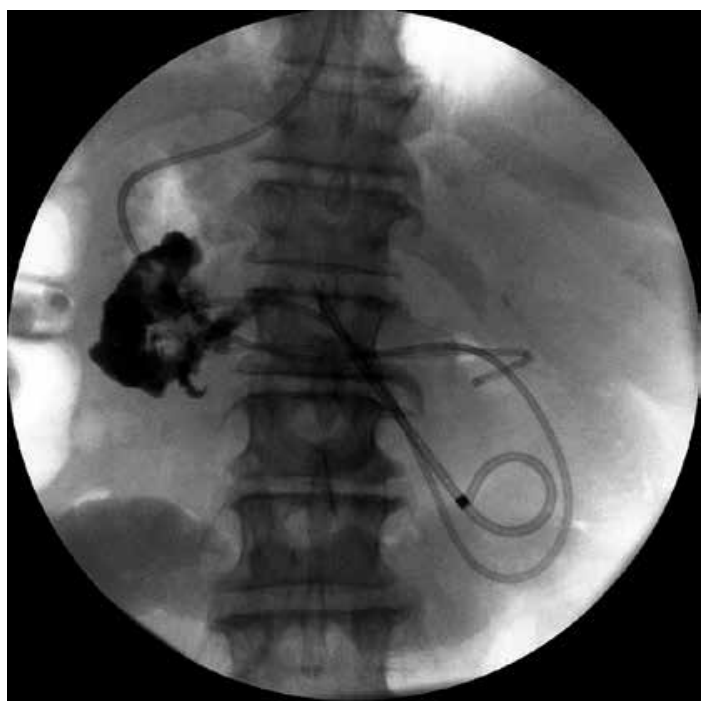

Figure 4. Transpapillary drainage of the WOPN performed. The procedure revealed a complete disruption of the main pancreatic duct (MPD). Part of the MPD in the head of the pancreas was contrasted through the major duodenal papilla, from where the contrast flowed down to the cavity of the WOPN (Figure 3). Sphincterotomy was performed before a mechanical dilatation of the MPD in the head of the pancreas using a 10-Fr dilatator. A transpapillary 8-Fr nasocystic drain and 10-Fr pancreatic stent were inserted (Figure 4). The decision to perform the endoscopic necrosectomy was made due to the presence of tissue elements in the cavity of the collection (Figure 5). The numerous necrotic tissues were removed through the major duodenal papilla using the Dormia basket under fluoroscopy imaging (Figure 6). Endoscopic necrosectomy was performed three times during the drainage. After 42 days of active trans-
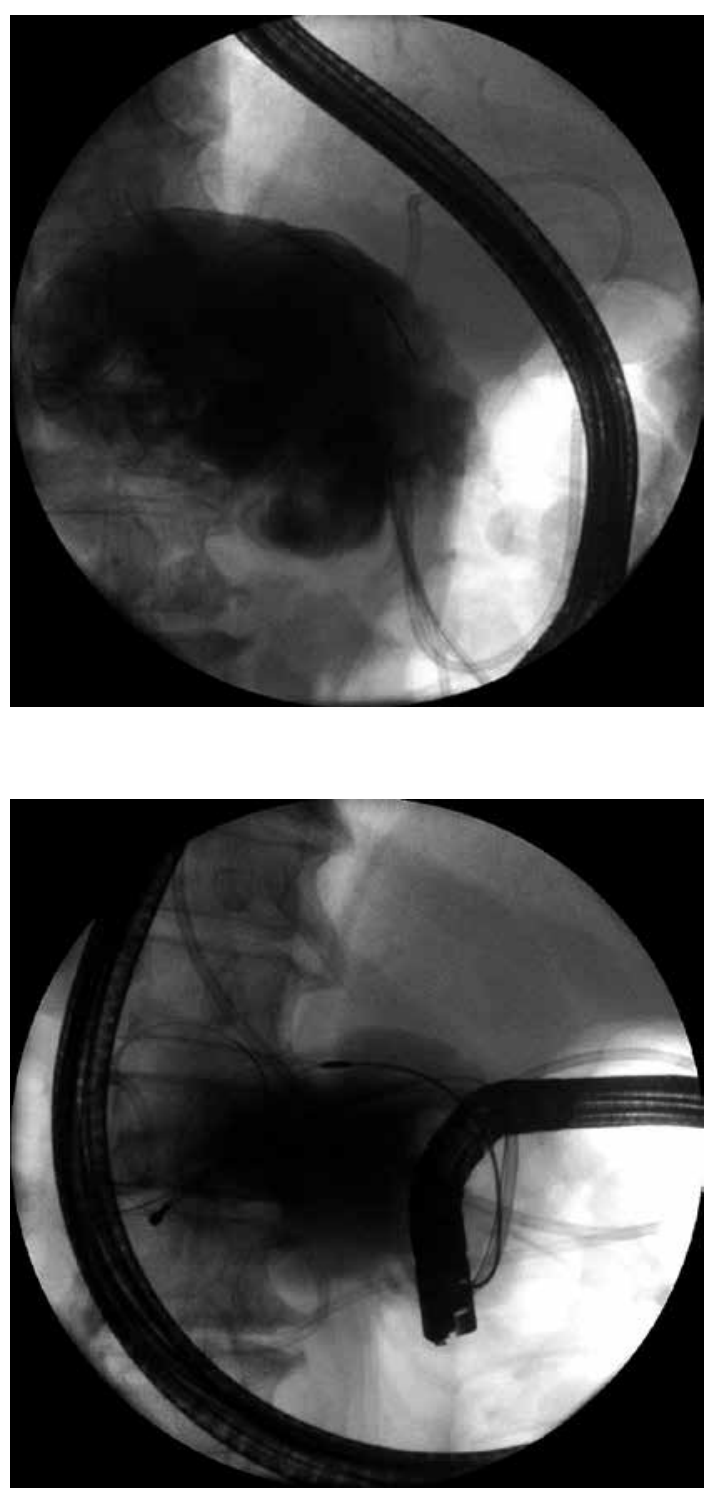

Figure 5. Endoscopic necrosectomy under fluoroscopy imaging. The Dormia basket was inserted in the collection of the necrosis 

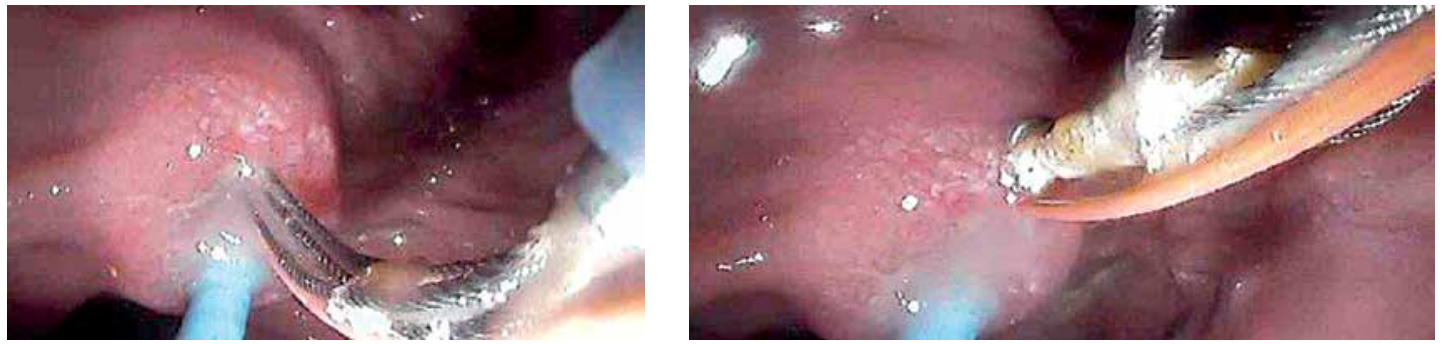

Figure 6. Endoscopic necrosectomy under fluoroscopy imaging. The nasocystic drain was guided through the major duodenal papilla in the cavity of the WOPN

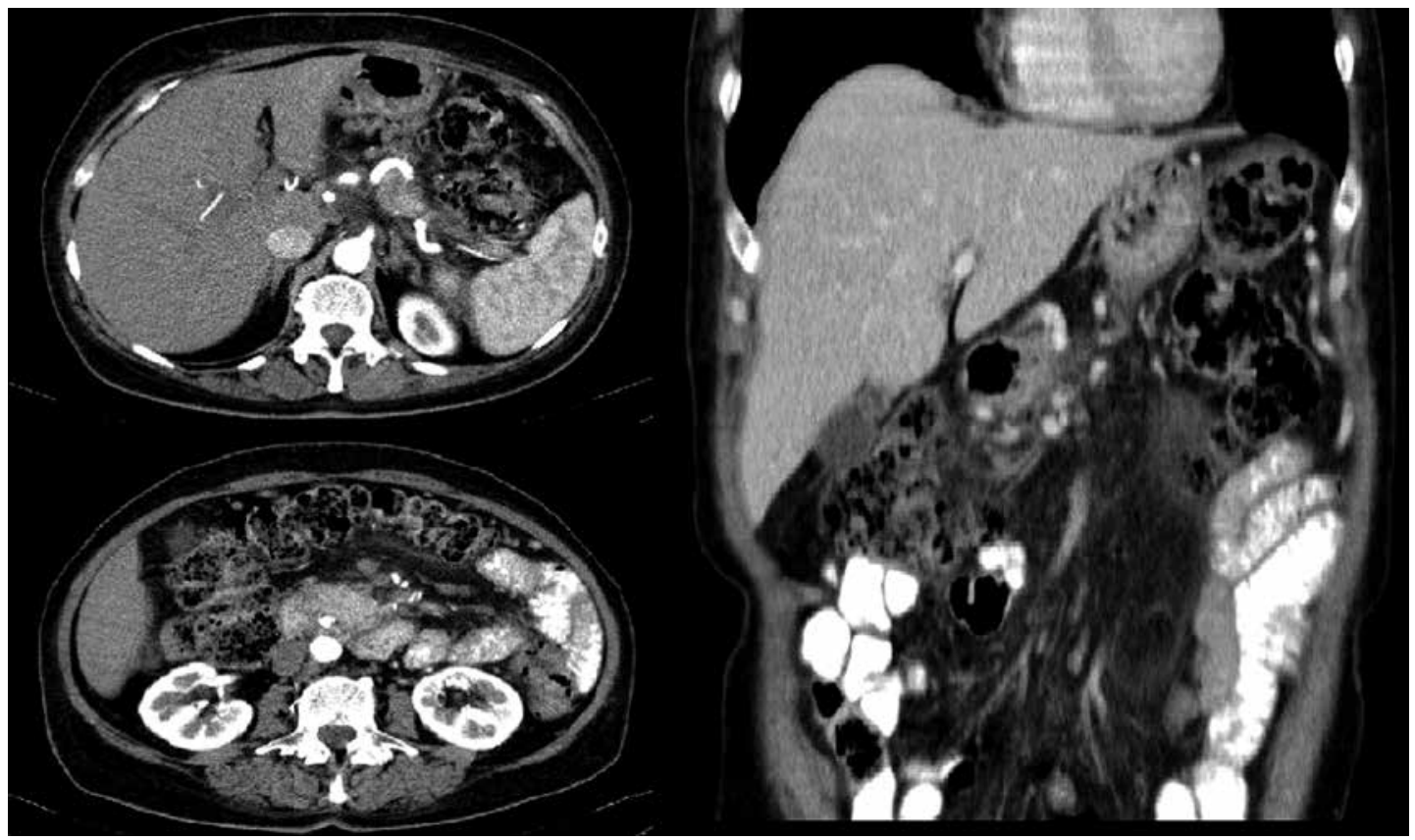

Figure 7. Contrast-enhanced computed tomography of the abdomen performed after endoscopic treatment

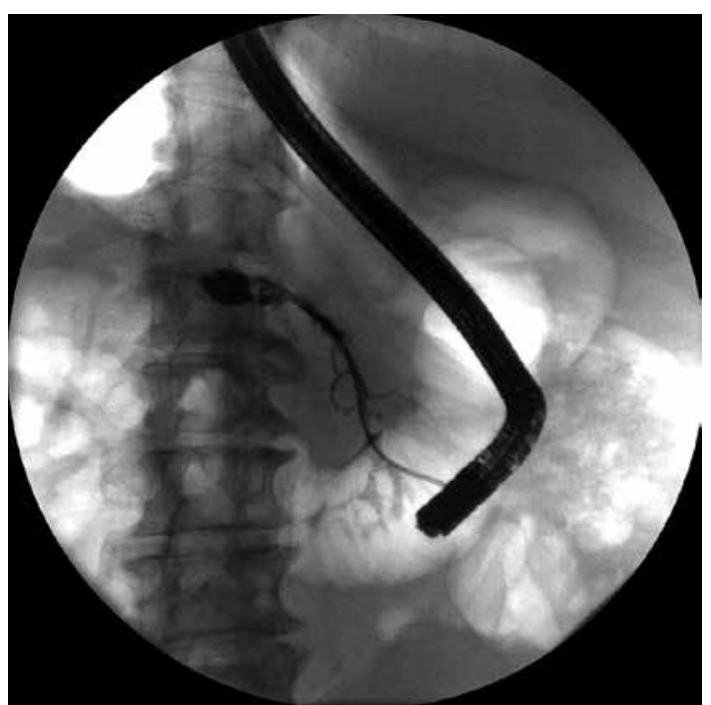

Figure 8. Endoscopic retrograde pancreatography after the passive drainage of the necrosis

mural drainage and 30 days of active transpapillary drainage, clinical symptoms resolved. Regression of the WOPN (collection $<3 \mathrm{~cm}$ ) was observed, which enabled removal of the nasocystic drain, leav- ing transmural and transpapillary stents in order to avoid return of the collection. During the next hospitalization and three months after the end of active drainage, CECT of the abdomen (Figure 7) indicated complete regression of the collection. This allowed transmural and transpapillary stents to be removed (Figure 8). After the therapeutic process the patient formally allowed our team to publish her case of treatment for scientific purposes.

\section{Conflict of interest}

The authors declare no conflict of interest.

\section{References}

1. Freeman ML, Werner J, van Santvoort HC, et al. Interventions for necrotizing pancreatitis: summary of a multidisciplinary consensus conference. Pancreas 2012; 41: 1176-94.

2. Loveday BP, Petrov MS, Connor S, et al. A comprehensive classification of invasive procedures for treating the local complications of acute pancreatitis based on visualization, route, and purpose. Pancreatology 2011; 11: 406-13. 
3. Bello B, Matthews JB. Minimally invasive treatment of pancreatic necrosis. World J Gastroenterol 2012; 18: 6829-35.

4. van Baal MC, van Santvoort HC, Bollen TL, Bakker OJ, Besselink MG, Gooszen HG. Systematic review of percutaneous catheter drainage as primary treatment for necrotizing pancreatitis. Br J Surg 2011; 98: 18-27.

5. Carter CR, McKay CJ, Imrie CW. Percutaneous necrosectomy and sinus tract endoscopy in the management of infected pancreatic necrosis: an initial experience. Ann Surg 2000; 232: 175-80.

6. Connor S, Ghaneh P, Raraty M, et al. Minimally invasive retroperitoneal pancreatic necrosectomy. Dig Surg 2003; 20: 270-7.

7. Raraty MG, Halloran CM, Dodd S, et al. Minimal access retroperitoneal pancreatic necrosectomy: improvement in morbidity and mortality with a less invasive approach. Ann Surg 2010; 251: 787-93.

8. Horvath K, Freeny P, Escallon J, et al. Safety and efficacy of video-assisted retroperitoneal debridement for infected pancreatic collections: a multicenter, prospective, single-arm phase 2 study. Arch Surg 2010; 145: 817-25.

9. Connor S, Alexakis N, Raraty MG, et al. Early and late complications after pancreatic necrosectomy. Surgery 2005; 137: 499-505.

10. Horvath KD, Kao LS, Ali A, Wherry KL, Pellegrini CA, Sinanan MN. Laparoscopic assisted percutaneous drainage of infected pancreatic necrosis. Surg Endosc 2001; 15: 677-82.

11. van van Santvoort HC, Besselink MG, Bollen TL, Buskens E, van Ramshorst B, Gooszen HG. Casematched comparison of the retroperitoneal approach with laparotomy for necrotizing pancreatitis. World I Surg 2007; 31: 1635-42.

12. Baron TH, Kozarek RA. Endotherapy for organized pancreatic necrosis: perspectives after 20 years. Clin Gastroenterol Hepatol 2012; 10: 1202-7.

13. Baron TH. Endoscopic drainage of pancreatic fluid collections and pancreatic necrosis. Tech Gastrointest Endosc 2004; 6: 91-9.

14. Smoczyński M, Marek I, Dubowik M, et al. Endoscopic drainage/debridement of walled-off pancreatic necrosis - single center experience of 112 cases. Pancreatology 2014; 14: 137-42.

15. Gardner TB, Coelho-Prabhu N, Gordon SR, et al. Direct endoscopic necrosectomy for the treatment of walledoff pancreatic necrosis: results from a multicenter U.S. series. Gastrointest Endosc 2011; 73: 718-26.

16. Papachristou GI, Takahashi N, Chahal P, Sarr MG, Baron TH. Peroral endoscopic drainage/debridement of walled-off pancreatic necrosis. Ann Surg 2007; 245: 943-51.

17. Seifert H, Biermer M, Schmitt W, et al. Transluminal endoscopic necrosectomy after acute pancreatitis: a multicentre study with long-term follow-up (the GEPARD Study). Gut 2009; 58: 1260-6.

18. Parekh D. Laparoscopic-assisted pancreatic necrosectomy: a new surgical option for treatment of severe necrotizing pancreatitis. Arch Surg 2006; 141: 895-902.

19. Wani SV, Patankar RV, Mathur SK. Minimally invasive approach to pancreatic necrosectomy. J Laparoendosc Adv Surg Tech A 2011; 21: 131-6.

20. Zhu JF, Fan XH, Zhang XH. Laparoscopic treatment of severe acute pancreatitis. Surg Endosc 2001; 15: 146-8.

21. Tan J, Tan H, Hu B, et al. Short-term outcomes from a multicenter retrospective study in China comparing laparoscopic and open surgery for the treatment of infected pancreatic necrosis. J Laparoendosc Adv Surg Tech A 2012; 22: 27-33.

22. Baron TH, Thaggard WG, Morgan DE, Stanley RJ. Endoscopic therapy for organized pancreatic necrosis. Gastroenterology 1996; 111: 755-64.

23. Seifert H, Wehrmann T, Schmitt T, Zeuzem S, Caspary WF. Retroperitoneal endoscopic debridement for in fected peripancreatic necrosis. Lancet 2000; 356: 653-5.

24. Seewald S, Groth S, Omar S, et al. Aggressive endoscopic therapy for pancreatic necrosis and pancreatic abscess: a new safe and effective treatment algorithm (videos). Gastrointest Endosc 2005; 62: 92-100. 